\title{
Death certification: increased clinical confidence in diagnosis and lack of interest in confirmation by necropsy is not justified
}

\author{
BARBARA KAR WINSKI, FLORA HARTVEIT \\ From the Department of Pathology, The Gade Institute, The University of Bergen, Norway
}

SUMMARY Comparison of 742 necropsies from 1975 with 833 from 1984 showed that the degree of certainty the clinicians attached to their diagnosis of the underlying cause of death had increased significantly in 1984. This was due almost exclusively to an increase in the certainty of the diagnosis of circulatory disease. Unfortunately, this was not justified as the numbers of false positive and false negative diagnoses were high in both years. With this increased certainty came a lack of interest in the necropsy. Similar lack of interest was also shown by surgeons in 1984, though in this instance it was accompanied by a high level of agreement between their diagnoses and necropsy findings.

The clinical and necropsy assessments of the cause of death in 742 patients, carried out at this institute in 1975, were compared and the data published in $1977 .{ }^{1}$ A corresponding analysis has now been completed for 1984. This paper compares the findings in these two years, including changes in the range of necropsy diagnoses, the attitude of the referring clinician, and the degree of certainty attributed by the clinician to the clinical diagnosis of the cause of death.

\section{Material and methods}

The necropsy material from this department was analysed for 1984 with a protocol similar to that used for $1975 .^{1}$ In 1975809 necropsies were carried out, $75 \%$ of all hospital deaths. In 1984 the number of necropsies increased to $835(81 \%)$. In both years the reason why necropsy was not carried out was mainly administrative: the distribution of clinical diagnoses in these cases was similar to that in the necropsy material, and so should not bias the results.

In 1984 a necropsy request form with additional questions, as used in the previous study, was received in 833 cases. The form gave the clinician's assessment of the cause of death, as judged by the doctor on duty using the case notes. (The request form was missing in two cases compared with a figure of 65 of 809 cases in 1975.) The cause of death had been classified by the clinician as certain or uncertain in 685 cases $(82 \%)$ in 1984 ; thus in $18 \%$ the additional questions on the form about the certainty of the clinical diagnosis were not answered. The corresponding figure for 1975 was 67 cases (8\%). In 1984 necropsy was classed as essential, desirable, or of little interest in 759 cases $(91 \%)$. When the degree of need had not been evaluated (76 cases, $9 \%$ ) the case was classified as desirable on the assumption that the form would not have been used had necropsy not been intended. Forensic cases were not included in either year.

The causes of death were classified using the 17 main diagnostic groups ${ }^{2}$ and the corresponding A-list of 150 groups. The material was also divided according to age

Table 1 Percentage distribution of necropsy cases related to WHO 17 main diagnostic groups in 1975 and $1984^{2}$

\begin{tabular}{lrr}
\hline & \multicolumn{2}{l}{ Necropsy $(\%)$} \\
\cline { 2 - 3 } WHO diagnostic group & 1975 & 1984 \\
\hline I & 1 & 1 \\
II neoplasia & 25 & 42 \\
III & 1 & 1 \\
IV & 1 & 1 \\
V & 1 & 0 \\
VI & 1 & 1 \\
VII circulatory system disease & 46 & 35 \\
VIII respiratory system disease & 6 & 6 \\
IX digestive system disease & 4 & 2 \\
X & 2 & 1 \\
XI & 0 & 1 \\
XII & 0 & 0 \\
XIII & 1 & 0 \\
XIV & 3 & 2 \\
XV & 6 & 6 \\
XVI & 1 & 1 \\
XVII & 3 & 1 \\
\hline
\end{tabular}


14

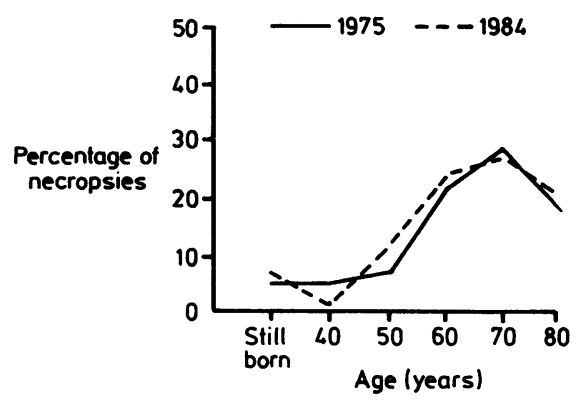

Fig 1 Percentage distribution of necropsy cases in both years ( $n=742$ in 1975 and $n=833$ in 1984) related to age.

and sex, and related to the different departments in the hospital.

The $\chi^{2}$ test was used for all statistical comparisons.

\section{Results}

In both 1975 and 1984, diagnostic groups II (neoplasia) and VII (diseases of the circulatory system) were best represented (table 1). The percentages of cases in these two groups were, however, reversed: the other groups showed little change. These data have been described in detail elsewhere. ${ }^{3}$

In both years there was a slight male predominance: 429 cases $(58 \%)$ in 1975 and 464 cases $(56 \%)$ in 1984. In 1984 there were fewer cases under 40 years, $\chi^{2}=9$, $\mathrm{p}<0.002$ (fig 1 ). The commonest age range in men (fig 2) was between 50 and 69 years and in women between 70 and 89 years, which was similar to that reported in 1975.

In 1975 agreement between the clinical and necropsy diagnoses of the cause of death ${ }^{1}$ was reached in 603 cases $(81 \%)$. This increased to 737 cases $(88 \%)$ in 1984, but this was not significant. Improvement in clinical diagnosis was noted in groups II, VIII (diseases of the respiratory system), and IX (diseases of the digestive system $)(86 \% v 95 \%, 44 \% v 71 \%$, and $46 \% v$

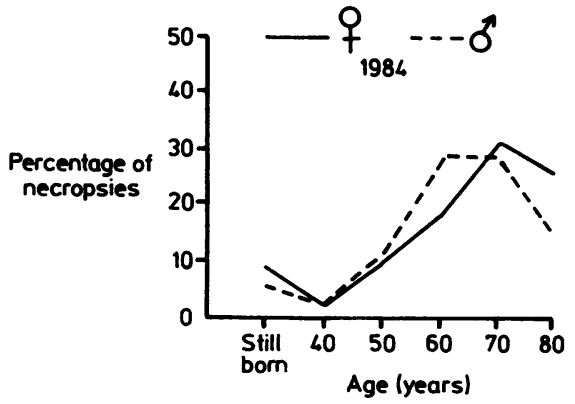

Fig 2 Percentage age distribution of necropsy cases in 1984 related to sex $($ males $=464$, females $=369)$.
Karwinski, Hartveit

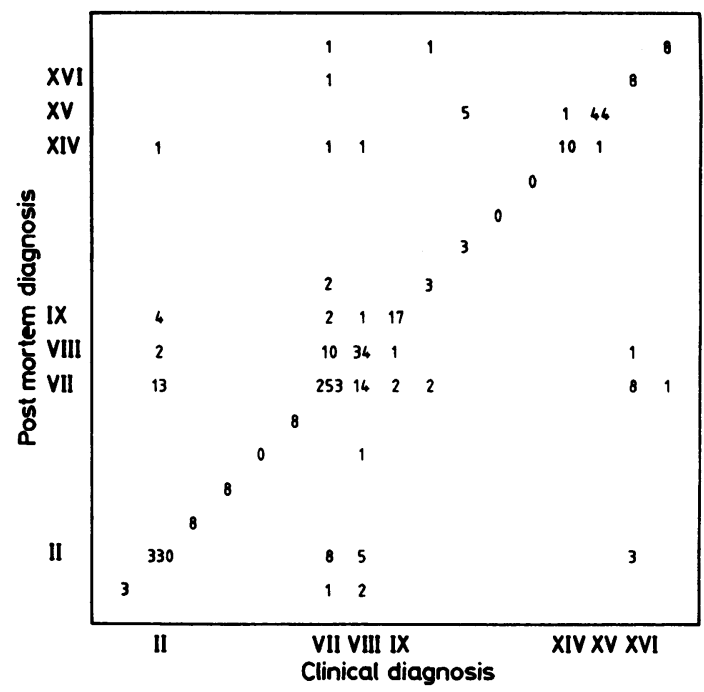

Fig 3 Distribution of diagnostic groups in 1984, relative to clinical and necropsy findings (false negative cases above the diagonal showing agreement, false positive cases underneath).

$70 \%$, respectively), but this was also not significant. There was no change in group VII ( $86 \%$ in both years) (fig 3).

There were $96(12 \%)$ cases where agreement on the cause of death was not reached. The sex distribution was equal; 84 cases $(87 \%)$ were over 70 years. There was thus an overall reduction in the total number of false positive and false negative diagnoses from $19 \%$ (139 cases) to $12 \%$ (96 cases), $p<0.0005$. In both years overdiagnosis (false positive) and underdiagnosis (false negative) resulted in an equal distribution of the figures. ${ }^{4}$ There was a significant reduction in total false positive and false negative diagnoses in group II ( $p<0.01$ and $p<0.0005$, respectively), but no significant changes in the others. While agreement was reached in 330 cases of neoplasia, 20 false positive and 16 false negative diagnoses were made. In group VII no changes were found. In 1984 agreement was

Table 2 Percentage distribution of necropsy cases in 1984 in groups II and VII related to hospital departments

\begin{tabular}{lll}
\hline & \multicolumn{2}{l}{ Percentage of necropsies } \\
\cline { 2 - 3 } Department & Neoplasia & Circulatory diseases \\
\hline Medical & 21 & VII \\
Surgical & 31 & 81 \\
Oncology & 16 & 9 \\
Chest & 19 & 0 \\
Maternity & 7 & 3 \\
Paediatrics & 0 & 0 \\
Neurology & 3 & 2 \\
Other & 3 & 2 \\
\hline
\end{tabular}


Table 3 Distribution of necropsy cases in 1975 and 1984 related to certainty of clinical diagnosis

\begin{tabular}{|c|c|c|c|c|}
\hline \multirow{3}{*}{$\begin{array}{l}\text { WHO diagnostic } \\
\text { group }\end{array}$} & \multicolumn{4}{|c|}{ Number of necropsies (\%) } \\
\hline & \multicolumn{2}{|l|}{ Certain } & \multicolumn{2}{|c|}{ Total } \\
\hline & 1975 & 1984 & 1975 & 1984 \\
\hline $\begin{array}{l}\text { All } \\
\text { Neoplasia } 45-61 \\
\text { Ischaemic heart and } \\
\text { cerebrovascular } \\
\text { disease } 83+85^{*}\end{array}$ & $\begin{array}{l}404(54) \\
148(72) \\
d \\
129(43)\end{array}$ & $\begin{array}{l}534(64) \\
268(77)\end{array}$ & $\begin{array}{l}742 \\
205\end{array}$ & $\begin{array}{l}833 \\
346\end{array}$ \\
\hline
\end{tabular}

*Degree of certainty $60 \%$ in 1984 for groups VII (diseases of the circulatory system) as a whole.

reached in $253(86 \%)$ cases with 26 false positive and 40 false negative diagnoses (fig 3).

Most of the false positive and false negative diagnoses came from the medical wards. The medical department was responsible for most of the group VII diagnoses, 238 cases $(81 \%)$, and the surgical department for many of group II 107 cases $(31 \%)$ (table 2 ). All cases derived from the oncology department were diagnosed as group II.

The clinical certainty of all diagnoses rose from 404 cases $(54 \%)$ in 1975 to 534 cases $(64 \%)$ in $1984(\mathrm{p}<$ 0.02 ) (table 3). Increase in certainty from 129 cases $(43 \%)$ to 140 cases $(60 \%)$ was found with ischaemic heart disease and cerebrovascular disease. This difference is significant $(p<0.02)$. In contrast, group II showed little change.

In both years about half of the cases came from the medical and a quarter from the surgical department (table 4). There was an increase in the certainty of the physicians' clinical diagnoses in 1984 : 175 cases $(42 \%)$ to 234 cases $(64 \%), p<0.005$. In the other departments the degree of certainty remained unchanged, except for paediatrics which decreased from 30 cases $(80 \%)$ to nine cases $(53 \%)$. Here, however, the number

Table 4 Distribution of necropsy cases in 1975 and 1984 between hospital departments related to certainty of clinical diagnosis

\begin{tabular}{|c|c|c|c|c|}
\hline \multirow[b]{3}{*}{ Department } & \multicolumn{4}{|c|}{ No of necropsies (\%) } \\
\hline & \multicolumn{2}{|l|}{ Certain } & \multicolumn{2}{|l|}{ Total } \\
\hline & 1975 & 1984 & 1975 & 1984 \\
\hline $\begin{array}{l}\text { Medical } \\
\text { Chest } \\
\text { Oncology* } \\
\text { Surgical } \\
\text { Paediatrics } \\
\text { Maternity } \\
\text { Neurology } \\
\text { Other }\end{array}$ & $\begin{array}{l}175(42) \\
70 \\
78 \\
30(80) \\
27 \\
13 \\
11\end{array}$ & $\begin{array}{l}234(64) \\
66 \\
50(86) \\
96 \\
9(53) \\
44 \\
14 \\
21\end{array}$ & $\begin{array}{l}416(56) \\
82 \\
119(16) \\
37 \\
44 \\
22 \\
22\end{array}$ & $\begin{array}{l}366(44) \\
92 \\
58 \\
158(19) \\
17 \\
83 \\
17 \\
42\end{array}$ \\
\hline
\end{tabular}

*In 1975 mostly included in medical department.
Table 5 Distribution of necropsies in 1975 and 1984 according to sex and age, related to clinical assessment of need for necropsy

\begin{tabular}{|c|c|c|c|c|}
\hline \multirow{3}{*}{$\begin{array}{l}\text { WHO diagnostic } \\
\text { group }\end{array}$} & \multicolumn{4}{|c|}{ No of necropsies (\%) } \\
\hline & \multicolumn{2}{|l|}{ Essential } & \multicolumn{2}{|c|}{ Little interest } \\
\hline & 1975 & 1984 & 1975 & 1984 \\
\hline $\begin{array}{l}\text { All } \\
\text { Certain } \\
\text { Total }\end{array}$ & $\begin{array}{c}89 \\
241 \text { (33) }\end{array}$ & $\begin{array}{l}75 \\
168(20)\end{array}$ & $\begin{array}{l}32 \\
45(6)\end{array}$ & $\begin{array}{l}107 \\
134(16)\end{array}$ \\
\hline $\begin{array}{l}\text { Neoplasia 45-61 } \\
\text { Certain } \\
\text { Total }\end{array}$ & $\begin{array}{l}35 \\
65(32)\end{array}$ & $\begin{array}{l}17 \\
31(8)\end{array}$ & $\stackrel{9}{10(2)}$ & $\begin{array}{l}25 \\
32(9)\end{array}$ \\
\hline \multicolumn{5}{|c|}{$\begin{array}{l}\text { Ischaemic heart and } \\
\text { cerebrovascular } \\
\text { disease } 83 \text { and } 85\end{array}$} \\
\hline $\begin{array}{l}\text { Certain } \\
\text { Total }\end{array}$ & $\begin{array}{l}15 \\
69(23)\end{array}$ & $\begin{array}{l}14 \\
37(17)\end{array}$ & $\stackrel{9}{12(4)}$ & $\begin{array}{l}33 \\
44 \text { (19) }\end{array}$ \\
\hline
\end{tabular}

of cases was low ( $n=37$ and 17). The greatest degree of certainty ( 50 cases, $86 \%$ ) was from the department of oncology.

Overall, in both years most necropsies were categorised as desirable and the percentage of cases in this group remained unchanged. There was a reduction in necropsies considered to be essential (table 5) with a parallel increase in those considered to be of little interest ( $p<0.0005$ in both years). The greatest drop in cases considered to be essential was in group II ( $p<$ $0.0005)$. In group VII (A-83 and 85$)$ the drop in the essential cases was accompanied by an increase in those of little interest $(p<0.0005)$. The medical and surgical departments both found necropsies to be of decreasing interest $(p<0.0005$ and $p<0.002$, respectively) (table 6).

In 1984 the highest percentage of essential necrop-

Table 6 Distribution of necropsy cases in 1975 and 1984 related to clinical assessment of need for necropsy

\begin{tabular}{llll}
\hline & & \multicolumn{2}{l}{ No of necropsies (\%) } \\
\cline { 3 - 4 } Department & Years & Essential & Little interest \\
\hline Medical & 1975 & $83(20)$ & $29(7)$ \\
& 1984 & $66(18)$ & $70(19)$ \\
Chest & 1975 & 24 & 4 \\
Oncology* & 1984 & 12 & 8 \\
Surgical & 1975 & -19 & 9 \\
& 1984 & $82(52)$ & $9(8)$ \\
Paediatrics & 1975 & $24(15)$ & $35(22)$ \\
& 1984 & 29 & 0 \\
Maternity & 1975 & 12 & 1 \\
Neurology & 1984 & $10(24)$ & 3 \\
Other & 1975 & $26(32)$ & 7 \\
& 1984 & 11 & 0 \\
& 1975 & 3 & 2 \\
& 1984 & 22 & 0 \\
& 1975 & 17 & 2
\end{tabular}

*In 1975 mostly included in medical department. 

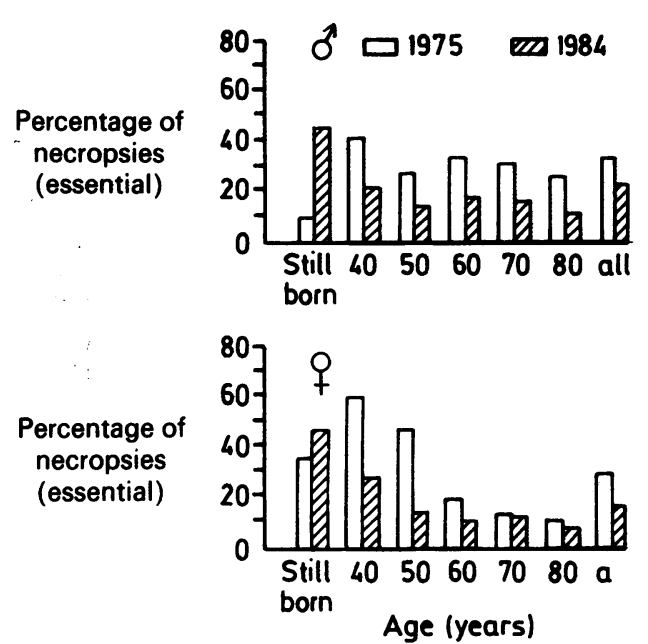
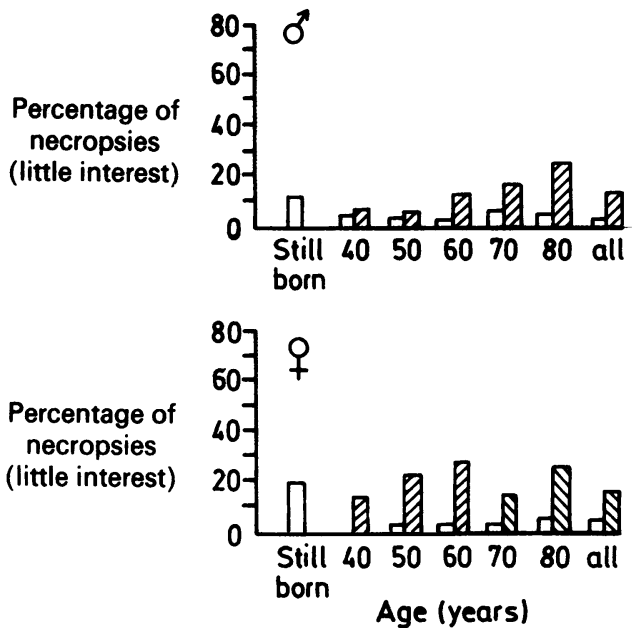

Fig 4 Percentage distribution of necropsy cases in both years estimated by the clinicians as essential $(n=241$ in 1975 and $n=168$ in 1984) or of little interest $(n=45$ in 1975 and $n=134$ in 1984) related to sex and age.

sies was recorded in stillborn infants (an increase was recorded for males) (fig 4). In all other groups the percentage was lower in 1984, with a tendency for necropsies to decrease with age, particulary in women. Those of little interest increased in both sexes in 1984, especially in women.

\section{Discussion}

Unlike most centres, ${ }^{5-9}$ the incidence of necropsy at this hospital, which has always been high, has increased over recent years. The clinicians' estimate of the degree of certainty of the clinical diagnosis of the cause of death was higher in 1984 than it was in 1975. A similar level of certainty has also been reported from other centres. ${ }^{10}$ The increase was due almost exclusively to increased certainty about diagnosing circulatory diseases. In all, $238(81 \%)$ cases in this group came from the medical department. This is in keeping with the finding that the degree of certainty for all diagnoses from the medical department increased from 175 cases $(42 \%)$ to 234 cases $(64 \%)$. Other departments did not show a corresponding increase.

This increase in certainty was, unfortunately, not justified on the basis of the necropsy findings. The number and distribution of false negative and false positive diagnoses in group VII was similar in both years studied, as was the level of agreement between clinical diagnosis and necropsy findings. Cases of sudden death later found to be due to cardiac disease accounted for much of this discrepancy.

On the other hand, agreement between the clinical and necropsy diagnoses increased slightly $737(88 \%)$ cases compared with $603(81 \%)$ mainly due to cases in groups II and VIII, which is in keeping with a report from Scotland. " Other workers have shown that there has been little improvement in the level of diagnostic accuracy for several decades. ${ }^{12-15}$ In 1984 the cause of death was changed in 96 cases $(12 \%)$, and most of them were over 70 years, in keeping with other recent reports. ${ }^{10116-18}$ It is striking that there was no change whatsoever in group VII. This is also apparent from other studies. ${ }^{118}$ There was also a tendency to overlook cardiac deaths in patients with confirmed cancer (fig 3).

Agreement for neoplasia was at a high level in both years, with an increase in $1984(86-95 \%)$, in contrast to the findings of other studies. ${ }^{1219} 19$ These oncology patients are usually well investigated both as in- and outpatients before their final admission. ${ }^{20}$ There was, however, an increasing lack of interest in necropsies in this group which may affect future results. ${ }^{6141521}$ Agreement in respiratory disease (group VIII) improved, due to a reduction in false negative diagnoses.

The present findings illustrate a growing lack of interest in necropsy on the part of clinicians. This is most apparent in patients over 70 years, in whom discrepancy as to the cause of death was greatest. ${ }^{141022}$ A strong exception was seen in stillborn infants. Here the recent appointment of a specialist in medical genetics is probably responsible. This underlines an important point: for a necropsy to be of interest to clinicians the case must present a special problem that they have not solved to their own satisfaction. The need for further investigation is thus paramount. When they feel satisfied that the case is clear cut, necropsy, though theoretically desirable, is in fact of little interest to them. This seems to have been the situation in the surgical department. In contrast, many 
of the elderly patients dying in the medical wards probably did not present relevant therapeutic problems. ${ }^{23}$

Now, as in 1975, the more active the treatment, the more involved the clinician, the greater his or her need for necropsy. Problems the clinicians have not recognised (false positive and negative diagnoses) still occur frequently. These are not minor differences, but total disagreement as to the cause of death in these patients. Herein lies the justification for the continued use of the necropsy as a final audit, particularly in teaching wards.

Our thanks are due to our colleagues in all departments of this hospital. The work was supported by the Norwegian Cancer Society.

\section{References}

1 Hartveit F. Clinical and post-mortem assessment of the cause of death. J Pathol 1977;123:193-210.

2 World Health Organization. Manual of the international statistical classification of disease. 8th revision. Geneva: WHO, 1966.

3 Hartveit F, Karwinski B. Changes in autopsy profile-1975 and 1984. J Pathol 1987;153:91-8.

4 Cameron HMA, McGoogan E. A prospective study of 1152 hospital autopsies: inaccuracies in death certification. J Pathol 1981;133:273-83.

5 Hasson J, Gross $\mathrm{H}$. The autopsy and quality assessment of medical care. Am J Med 1974;56:137-40.

6 Cameron HMA. The autopsy, past and present. J Roy Coll Phys Lond 1984;4:236-9.

7 Price RA, McCormick WF. The declining autopsy rate and its significance for neuropathology: two viewpoints. J Neuropathol Exp Neurol 1981;40:489-92.

8 Roberts WC. The autopsy: its decline and a suggestion for its revival. N Engl J Med 1978;299:332-8.

9 Svendsen E, Hill RB. Autopsy legislation and practice. Arch Pathol Lab Med 1987;111:846-50.

10 Cameron HMA, McGoogan E, Watson H. Necropsy: a yardstick for clinical diagnosis. $\mathrm{Br} \mathrm{Med} J$ 1980;281:985-8.

11 Goldman L. The value of the autopsy in three medical eras. $N$ Engl $J$ Med 1983;308:1000-5.

12 Stevanovic G, Tucakovic G, Dotlic R, Kanjuh V. Correlation of clinical diagnoses with autopsy findings: A retrospective study of 2,145 consecutive autopsies. Hum Pathol 1986;12:1225-30.

13 Silverberg S. The autopsy and cancer. Arch Pathol Lab Med 1984;108:476-8.

14 Goldman L. Diagnostic advances and the value of the autopsy. Arch Pathol Lab Med 1984;108:501-5.

15 McGoogan E. The autopsy and clinical diagnosis. J Roy Coll Phys Lond 1984;18:240-3.

16 Schned AR, Mogielnicki P, Stauffer ME. A comprehensive quality assessment program on the autopsy service. Am J Clin Pathol 1986;86:133-8.

17 Schottenfeld D. The autopsy as a measure of accuracy of the death certificate. Bull NY Acad Med 1982;58:778-94.

18 Gobbato F, Vecchiet F, Barbierato D, Melato A, Manconi R Inaccuracy of death certificate diagnoses in malignancy: an analysis of 1,405 autopsied cases. Hum Pathol 1982;13:1036-8.

19 Hartveit F. Time and place for sputum cytology in the diagnosis of lung cancer. Thorax 1981;36:299-302.

20 Gambino SR. The autopsy. Arch Pathol Lab Med 1984;108:444-5.

21 Puxty JAH, Horan MA, Fox RA. Necropsies in the elderly. Lancet 1983;i:1262-4.

22 Britton M. Diagnostic errors discovered at autopsy. Acta Med Scand 1974;196:203-10.

23 Coid J, Crome $\mathrm{P}$. Bed blocking in Bromley. $\mathrm{Br} \mathrm{Med} \mathrm{J}$ 1986;292:1253-6.

Requests for reprints to: Professor F Hartveit, Department of Pathology, 5016 Haukeland Hospital, Bergen, Norway. 